\title{
Maximilian Kummer
}

\section{Sprachprobleme und Sprachrisiken}

\author{
Lösungsansätze des Draft Common Frame of Reference
}

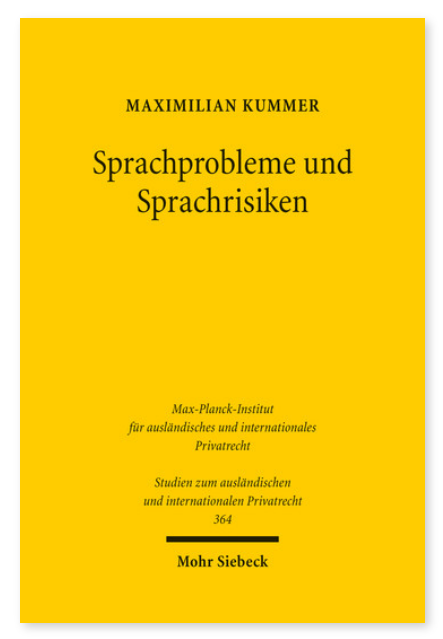

2016. XX, 285 Seiten. StudIPR 364

ISBN 978-3-16-154647-1

DOI 10.1628/978-3-16-154647-1

eBook PDF 79,00€

ISBN 978-3-16-154637-2

fadengeheftete Broschur 79,00€
Um Verträge auszuhandeln, sie abzuschließen oder Streitfragen im Zusammenhang mit ihrem Zustandekommen und ihrer Ausführung zu lösen, bedarf es der Kommunikation. Sprache ist das Medium jeder juristischen Interaktion. Maximilian Kummer untersucht anhand des Entwurfs für einen europäischen Referenzrahmen des Privatrechts (DCFR), ob der Umstand, dass Missverständnisse in grenzüberschreitenden Sachverhalten vermehrt auftreten, bei den europäischen Bemühungen einer Privatrechtsvereinheitlichung ausreichend berücksichtigt wird. Dazu evaluiert er zunächst den Umgang der Vorschriften des DCFR mit Sprachproblemen oder Missverständnissen auf verschiedenen Ebenen des Vertragsrechts wie dem Zugang, der Auslegung oder der Anfechtung. Daran schließt sich eine Betrachtung solcher Vorschriften des DCFR an, welche in unterschiedlichem Maße direkt oder indirekt Einfluss auf die Sprachverwendung im Rechtsverkehr nehmen.

Maximilian Kummer Geboren 1989; Studium der Rechtswissenschaften in Augsburg; 2013 Erste juristische Prüfung wissenschaftlicher Mitarbeiter am Lehrstuhl für Bürgerliches Recht, Wirtschaftsrecht und Rechtsgeschichte an der Universität Augsburg; seit 2015 Rechtsreferendar am OLG Stuttgart.

Jetzt bestellen:

https://mohrsiebeck.com/buch/sprachprobleme-und-sprachrisiken-9783161546471?no_cache=1 order@mohrsiebeck.com

Telefon: +49 (0)7071-923-17

Telefax: $+49(0) 7071-51104$ 